\title{
The Welfare Effects of Index-Based Livestock Insurance: Livestock Herding on Communal Lands
}

\author{
Erwin Bulte $^{1} \cdot$ Rein Haagsma ${ }^{1}$
}

Accepted: 19 February 2021 / Published online: 12 March 2021

(c) The Author(s) 2021

\begin{abstract}
Agricultural (index) insurance for smallholders in developing countries has gained traction in academic and policy circles. The expectation is that the uptake of insurance will protect smallholders from production shocks and incentivize them to modernize production. We develop a simple theoretical model to demonstrate that the welfare effects of insurance are fundamentally ambiguous - even in the absence of transaction costs or basis risk. The second-best nature of the institutional context within which smallholders operate implies that the uptake of insurance may accentuate pre-existing inefficiencies. This idea is worked out in detail for the case of livestock herding on common grazing lands. Our theoretical model predicts that insurance invites overstocking of communal lands, and lowers the profitability of herding when common pastures are degraded.
\end{abstract}

Keywords Index insurance $\cdot$ Second-best analysis $\cdot$ Property rights $\cdot$ Overgrazing · Livestock

JEL Codes $\mathrm{G} 22 \cdot \mathrm{O} 13 \cdot \mathrm{O} 16 \cdot \mathrm{Q} 12$

\section{Introduction}

The promotion of agricultural insurance has gained a prominent position on the international development agenda. Across the African continent, hundreds of (pilot) initiatives have been rolled out-for either research purposes or commercial reasons-and in policy circles there is widespread support for efforts to promote the diffusion of insurance. The expectation is that the consumption-smoothing properties of insurance do not only enable smallholders to cope with adverse weather shocks without resorting to drastic measures such as selling key assets or taking children out of school, insurance can also be a catalyst for innovation and modernization of agriculture in Africa. An emerging literature suggests that the elimination of downside risk may "crowd in" modern

Erwin Bulte

Erwin.bulte@wur.nl

Rein Haagsma

Rein.haagsma@wur.nl

1 Development Economics Group, Wageningen University, 8700 EW Wageningen, Netherlands 
technologies, which is widely perceived as a necessary condition for the modernization of African agriculture in rain-fed production areas.

The majority of Africa's poor reside in rural areas, and their economic fate depends on the performance of the agricultural sector (World Bank 2007; Dercon et al. 2014). Economic growth originating in the agricultural sector is the most effective way to lift people out of poverty. It has large multiplier effects in early stages of development (Haggblade et al. 2007), and raises income of the poor more than growth originating elsewhere in the economy-especially for the poorest, and especially in early stages of development (Christiaensen et al. 2010), Moreover, various forward and backward linkages imply that agriculture may stimulate economic modernization elsewhere in society. However, while pockets of adoption and diffusion certainly exist, the adoption of modern technologies-including the uptake of improved varieties and fertilizer-has remained low (Foster and Rosenzweig 2010). As argued below, this situation may be remedied by the diffusion of insurance. However, as also argued below, such a process will involve extensive subsidization by the public sector as market-based diffusion of insurance remains very incomplete.

The main objective of this paper is to critically evaluate the expectation that the promotion of insurance will raise welfare in rural communities. While this conventional wisdom is intuitive, as expansion of the market for insurance implies relaxing a binding constraint for rural households and farms, we demonstrate it is flawed. Our theoretical model suggests the reverse may be true, or at least that the welfare effects of the uptake of insurance are typically ambiguous. We derive conditions under which adoption of insurance will reduce (expected) income and result in environmental degradationattenuating any utility gains from consumption smoothing, and perhaps even reversing them.

The reason for these adverse effects is the second-best nature of the institutional context within which insurance is traded. We develop a theoretical model, based on standard economic assumptions, to demonstrate how (index-based) drought insurance accentuates pre-existing inefficiencies, and may lower welfare. The case we consider is index-based livestock insurance, and the second-best nature of the context is provided by the assumption that property rights to grazing land are imperfectly defined (or enforced). Individual herders gain from expanding their herd while sharing the cost of overgrazing with others. In this context, the adoption of insurance implies an incentive to over-stock beyond socially optimal levels. A new Nash equilibrium eventuates where all herders may be worse off than before, and where the common grazing ground has been depleted. Qualitatively similar processes may occur in the context of index based crop insurance as long as the following conditions are satisfied: (i) property rights to the natural environment are imperfect, (ii) insurance promotes intensification of farm management and increases pressure on the environment, and (iii) environmental quality enters the production or utility function of farmers (or both). We believe these conditions are general, and include cases such as the over-use of chemical inputs.

The focus on index-based livestock insurance is relevant as such schemes have recently been initiated in, for example, Mongolia, Kenya and Ethiopia. Similar initiatives may start up in other African countries, including Mauritania, Mali, Niger, Senegal, Somalia, South Africa, Uganda, Zambia and Zimbabwe (Castell 2017). Pastoralists who are affected by these initiatives are among the world's poorest; they live under quite adverse conditions and are vulnerable to weather shocks. For information about the design and impact of indexbased livestock insurance, refer to Chantarat et al. (2007), Chantarat et al. (2013), and for a simulation analysis of the welfare effects, refer to Chantarat et al. (2017). Importantly, the 
latter study does not include the mechanism that is our focus-the incentive for pastoralists to increase herd size, causing degradation of the pasture.

This paper is organized as follows. In Sect. 2 we discuss the recent literature on the insurance revolution that sweeps the African landscape. In Sect. 3 we sketch the components of our theoretical model. We set up the pastoralists' optimal stocking problem with and without insurance, and compare outcomes to the socially optimal stocking rate. In Sect. 4 we add vegetation dynamics, and evaluate the overall welfare effects. We also provide a simple numerical illustration. The discussion and conclusions ensue.

\section{Insuring African Agriculture}

An estimated 6\% of the agricultural land in Africa is irrigated, so yields and harvests of the great majority of African farmers depend on the vagaries of the weather. Weather conditions tend to be volatile, exposing farmers to both drought shocks as well as the risk of floods. Indirectly, through local linkages, weather-related risks also affect input suppliers (including credit providers), farm workers, and workers in agribusiness. The same is true for pastoral systems. Jensen et al. (2016) find that nearly 50\% of the livestock losses in Northern Kenya are due to drought-related starvation and dehydration. Can such risks be insured?

Until recently, few economists would have answered in the affirmative. Several factors have complicated the emergence of a thriving financial sector supplying traditional indemnity-based insurance. First, transaction costs are typically prohibitively high. Many smallholders have small plots and demand insurance in very small quantities, so that establishing the extent of damages at the farm level implies incurring excessive verification costs from a commercial perspective (loss adjustment costs). Second, indemnity insurance exposes the insurance provider to moral hazard and adverse selection by the insured buyer-a consequence of information asymmetries. Insured farmers may under-invest in soil- and water conservation techniques and choose risky crop mixes, increasing their exposure to downside risk. Moreover, indemnity insurance may especially induce "risky farmers" to purchase insurance. Third, weather shocks are so-called common covariate shocks, typically affecting large swaths of producers simultaneously. This covariance of risk causes delayed payments in case the insurance company lacks capacity to assess costs on a large scale, and also introduces problems of insolvency and liquidity for the insurance provider. Re-insurance on international capital markets provides a solution, but may be unavailable for indemnity insurance as re-insurance companies demand detailed data on farm-specific risks, which is usually not available.

Overcoming these challenges, a "new" approach to providing insurance to smallholder farmers has recently gained a lot of traction. So-called index insurance delinks insurance pay-outs from individual-level on-farm losses. Instead, farmers can purchase coverage based on an index that is correlated with these losses. Such indices may be based on average measures of biomass productivity (e.g. NDVI), average yield losses in a larger area, or on the amount of rain during a certain time period. These variables should be objectively quantifiable, easily verifiable, and not easily manipulated by the insurance provider or farmer. Pay-outs are triggered when the index falls short of a pre-determined threshold. One important reason for the improved popularity of index insurance is that technologies for upscaling by using satellite-based indices are increasingly becoming available. 
The advantages of index insurance are obvious. Transaction (verification) costs are much lower as pay-outs are not based on farm-level damages but on an objective variable such as local rainfall. Since pay-outs are delinked from the assessment of individual losses, problems due to moral hazard and adverse selection are attenuated or nearly eliminated (but see Jensen et al. 2018 for evidence of spatiotemporal adverse selection in the context of an index-based livestock insurance scheme). Insurance premiums can be reduced, increasing affordability of insurance for smallholders. In addition, since pay-outs are based on events for which the probability of pay-out can be precisely measured, the insurance product carries less risk for the insurance company. Indeed, because the insurance is based on reliable and independently verifiable information, re-insurance is relatively straightforward, and insurance companies can efficiently transfer part of the risk to international markets.

Beginning in the early 2000s, index insurance for weather shocks was introduced in pilot form in several countries (Sarris 2013), and now index insurance programs have been rolled out in more than 15 developing countries (Carter et al. 2017). While the majority of the index-based insurance initiatives focus on droughts and crops, there have also been efforts to insure livestock farmers against droughts - mitigating adverse effects on production, and animal morbidity and mortality (e.g., Chantarat et al. 2007, 2013). Regardless of the sector, most experts believe index insurance has the potential to improve the livelihoods of risk-averse farmers. The ability to smooth consumption and cope with shocks reduces the threat of famines and makes risk-averse farmers better off. As mentioned above, the benefits of insurance extend beyond such static utility gains. By preventing outcomes where smallholders are forced to sell their scarce productive assets to meet minimum consumption levels, insurance may prevent poor rural households from tumbling into a so-called "poverty trap." Moreover, the adoption of insurance allows households to focus more on maximizing expected profits, rather than minimizing risk.

A large literature has established that many smallholders opt for "low-risk-but-lowreturn" subsistence farming because this attenuates the risk of disastrous outcomes. In an older study, Walker and Ryan (1990) found that, on average, poor rural households in India were willing to sacrifice $25 \%$ of their average income in order to reduce exposure to shocks. The introduction of insurance enables the farmer to abandon their subsistence orientation and choose cropping patterns with greater expected returns (see also Mobarak and Rosenzweig 2013; Cai 2016; Elabed and Carter 2015). This idea is closely related to the adoption of new technologies and increased external input use. Two recent papers demonstrate that reducing downside risk invited a behavioral response towards intensification and modernization: Karlan et al. (2014) found that adopting drought insurance "crowded in" the use of fertiliser in Ghana, and Emerick et al. (2016) found that adoption of floodtolerant rice varieties achieved the same in India. ${ }^{1}$

In light of these potential benefits, it is not surprising that the introduction of index insurance met with great enthusiasm in policy circles and among academics (e.g., Hazell et al. 2010). However, Binswanger (2012) soon warned about "too much hype about

\footnotetext{
${ }^{1}$ Observe that insurance may also contribute towards transforming local capital markets. If smallholders can only obtain credit if they have collateral (say land), then the introduction of insurance makes borrowing more attractive because farmers do not have to fear losing their land (Boucher et al. 2008 refer to outcomes where farmers refrain from borrowing because of such fears as "risk rationing"). In contexts without collateral, or where liquidating collateral is expensive, the introduction of insurance may reduce risk for lenders-reducing risk premiums and increasing the affordability of loans for smallholders.
} 
index-based agricultural insurance." Indeed, it appears as if early expectations and excitement about index insurance were overblown. Voluntary take-up rates typically remain disappointingly low-oftentimes hovering below $10 \%$ of the target population. Ahmed et al. (2017, p. 32) write “... there are literally no examples of developing-country index insurance pilot programs leaping to scale as market-based products." This implies that extensive subsidies remain necessary in the near, and perhaps not-so-near, future to promote the diffusion of index-based drought insurance.

There are several reasons why index insurance has failed to take off and transform the African countryside. Index insurance only provides imperfect coverage for household shocks in case individual damages are not perfectly correlated with the index-as is typically the case when the nearest rainfall station is relatively far away from someone's farm (or if the grid size is too large in case of a satellite-based approach). While the index is hopefully correlated with individual losses, it is not identical to these losses and residual risk remains - known as "basis risk." It is possible that individual losses are high while the index does not reach the threshold, so that insured farmers are worse off than they would have been in the absence of insurance because they paid the premium (Clarke 2016). "False negatives" undermine the expected utility of adoption-especially for highly risk averse farmers. ${ }^{2}$ For evidence of the importance of basis risk in the context of livestock insurance, refer to Jensen et al. (2016) and Jensen et al. (2018). ${ }^{3}$

Of course there are other important reasons why smallholders may fail to adopt index insurance. For example, insurance products are "complex" and low levels of financial literacy among target populations imply not all potential beneficiaries understand its logic or recognise the potential benefits (e.g. Cole et al. 2014; Cai et al. 2015). Lack of experience with shocks may also matter, just as lack of knowledge about the precise probability of disaster (Cai and Song 2017; Bjerge and Trifkovic 2018). Another obvious impediment for poor households is lack of liquidity. The liquidity problem is aggravated by the possibility that the marginal utility of cash or income may not be consistent over time-varying across the seasons in accordance with income flows (Casaburi and Willis 2016). Insurance premiums are typically due when cash is scarce and any pay-outs are received after harvesting, when the marginal utility of cash is relatively low. This makes insurance more expensive from the perspective of poor farmers. Moreover, low levels of trust in insurance providers may introduce an additional risk premium from the farmers' perspective. Carter et al. (2017, p. 10.4) conclude:

the gap between the promise and reality of index insurance may create one of the most important current opportunities to designing new institutions that can help developing countries achieve the goal of increased investment in agriculture, accelerated growth, and poverty reduction.

To create the conditions under which index insurance can live up to its "promise" is now a lively field of research. In addition to the provision of subsidies to premiums, it may be possible to improve the insurance product. There are opportunities to better manage basis risk (e.g. Elabed et al. 2013), including selling insurance to groups of farmers with subsequent redistribution based on idiosyncratic needs (Dercon et al. 2014). Training interventions should build

\footnotetext{
${ }^{2}$ In fact, the combination of uncertain rainfall and uncertain pay-outs implies the farmer faces a compound lottery, inviting ambiguity aversion (Elabed and Carter 2015). For information about measuring loss aversion among farmers, refer to Bocqueho et al. (2014).

${ }^{3}$ For an innovative approach to deal with scarce data, refer to Shen et al. (2016).
} 
knowledge and trust. Delayed payment of insurance premiums, or bundling insurance with credit, attenuates the liquidity issue (e.g. Casaburi and Willis 2016). Perhaps a combination of such interventions will cause the insurance market in Africa to develop.

While the benefits of insurance, as discussed above, are real and important for smallholders and pastoralists, we argue that a potentially important risk has so far been ignored. In what follows we zoom in on this new feature, and ignore many aspects of the literature such as asymmetric information, basis risk and non-standard (i.e. "behavioral") preferences. We also gloss over important issues such as the spatial distribution of rainfall risk, potential migratory coping strategies and issues around grazing rights management - not because we believe these issues are unimportant, but because they would (further) complicate the model and obfuscate the mechanism we are interested in.

\section{The Static Model}

In this section we develop a theoretical model that allows probing the welfare effects of insurance. We study the case of multiple pastoralists sharing access to a common grazing ground. To simplify matters we abstract from investments in quality-herders are free to choose the size of their herd, but cannot invest in different (genetic) varieties and cannot invest in quality by providing veterinary care or supplemental feeding. Uptake of veterinary services tends to be low among pastoralists (e.g. Jensen et al. 2017). Another simplifying assumption is that herders seek to maximize utility, which is a concave function of profits. That is, herders do not accumulate herds as a (precautionary) savings device and do not derive any status from larger herds (but see Lybbert et al. 2004). In the discussion section below we will discuss how relaxing the assumptions of our standard economic model would affect the results.

A crucial element of our model is that production decisions of individual herders are linked via the common resource base. We consider the case of a social planner as well as the case of an unregulated common property and the Nash equilibrium that eventuates (e.g. Baland and Platteau 1996). In this section we provide an explicit solution for the effects of insurance on herder expected income and utility in the "short term." Pastoralists choose the number of animals based on the (known) distribution of rainfall which determines the availability of forage. In the next section we study the "long term" outcomes, after the grazing system has responded to the augmented animal stocks.

\subsection{Building Blocks}

Assume $N$ cattle farmers or pastoralists $(N \geq 2)$ have access to the same grazing ground, and that farmer $i$ chooses the size of his herd, $n_{i}$, to maximize expected utility:

$$
\max _{n_{i}} E\left[U\left(\pi\left(n_{i}, \mathbf{n}^{-i} ; V\right)\right)\right],
$$

where $\pi$ denotes profits, $\mathbf{n}^{-i}$ the total number of animals by other pastoralists, and $V$ the stock of vegetation. Assume that $V$ is a random variable, determined by stochastic rainfall in the short term (given animal stocks). Specifically, with $R$ denoting rainfall, we assume

$$
V=r_{1}+r_{2} R,
$$

where $r_{1}$ and $r_{2}$ are constants, $r_{2}>0$, and $R$ is normally distributed with positive expected value $\bar{R}$ and variance $\sigma_{R}^{2}$. Then $V$ is also normally distributed with expected value 
$\bar{V}:=r_{1}+r_{2} \bar{R}$ and variance $\sigma_{V}^{2}:=r_{2}^{2} \sigma_{R}^{2}$. (In the next section, we assume that the dynamics of $\mathrm{V}$ are governed by both rainfall and herd size.) In what follows we assume $V \geq 0$ (granting that the cumulative density at $V=0$ is negligibly small).

To fix ideas, we consider a simple quadratic profit function: ${ }^{4}$

$$
\pi\left(n_{i}, \mathbf{n}^{-i} ; V\right):=p_{p} n_{i}(V-\mathbf{n} v)-c,
$$

where $\mathbf{n}=n_{i}+\mathbf{n}^{-i}$ is the total livestock herd, $p_{p}$ is the price of a composite livestock product (meat, calves, milk), $v$ is a parameter measuring the extent of congestion, and $c$ is the fixed cost of production. Our production function captures that output of the composite good is (initially) increasing in pastoralist $i$ 's own herd, but decreasing in the total herd because of congestion externalities. This could be due to competition for forage, or due to the need for herds to travel greater distances in search of food and shelter if they share the habitat with other herds (where traveling consumes energy which lowers production). This is a crucial assumption of the model, implying that aggregate profit (production) equals zero when $\mathbf{n}=0$ or $\mathbf{n} v=V .{ }^{5}$ Aggregate production is nonnegative for $\mathbf{n} \in\left[0, \frac{V}{v}\right]$ and maximized when $\mathbf{n}=\frac{V}{2 v}$, or when each pastoralist has a herd size of $n_{i}=\frac{V}{2 N v}$.

In what follows we assume that pastoralists are risk-averse and have a utility function displaying constant absolute risk aversion (qualitatively similar results eventuate for alternative specifications of risk aversion):

$$
U(\pi):=1-e^{-k \pi}
$$

with $k>0$. To simplify notation, define

$$
\begin{gathered}
s_{1}\left(n_{i}, \mathbf{n}^{-i}\right):=-p_{p} n_{i} v\left(n_{i}+\mathbf{n}^{-i}\right)-c \\
s_{2}\left(n_{i}\right):=p_{p} n_{i}
\end{gathered}
$$

so that

$$
\pi=s_{1}\left(n_{i}, \mathbf{n}^{-i}\right)+s_{2}\left(n_{i}\right) V
$$

and we can write

$$
U(\pi):=1-e^{-k s_{1}} e^{-k s_{2} V} .
$$

Since $V$ is normally distributed, we know that $e^{-k s_{2} V}$ is log-normally distributed with

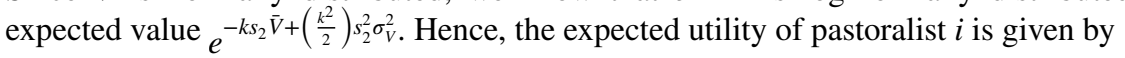

$$
E[U(\pi)]=1-e^{-k \pi\left(n_{i}, \mathbf{n}^{-i} ; \bar{V}\right)+\left(\frac{k^{2}}{2}\right) s_{2}\left(n_{i}\right)^{2} \sigma_{V}^{2}} .
$$

\footnotetext{
4 The main results hold for more general specifications, provided that the linearity in $V$ is preserved.

5 Importantly, the main insights of the model spill over to alternative model specifications without congestion externalities, as long as production is a function of the available vegetation stock (and the vegetation stocks responds to the overall number of animals). For example, it is possible to develop a model with convex production costs (rather than diminishing net returns), yielding an interior solution with respect to the privately optimal stock. In such a model the welfare costs of overgrazing do not materialize in the short run when vegetation is "given" . Instead, the negative externality associated with over-stocking will occur "over time" as the common pasture is degraded due to overgrazing (see Sect. 4).
} 


\subsection{Herd Size Without Insurance}

We first solve for the symmetric Nash equilibrium in the absence of insurance, where each individual pastoralist ignores the congestion externality and maximizes

$$
\max _{n_{i}}\left[p_{p} n_{i}\left(\bar{V}-\mathbf{n}^{-i} v-n_{i} v\right)-c-\frac{k}{2}\left(p_{p} n_{i}\right)^{2} \sigma_{V}^{2}\right],
$$

which gives

$$
n_{i}=\frac{\bar{V}}{2 v+k p_{p} \sigma_{V}^{2}} .
$$

It follows that in the symmetric Nash equilibrium, individual herd size is

$$
n_{i}^{*}=\frac{\bar{V}}{(N+1) v+k p_{p} \sigma_{V}^{2}} .
$$

This result may be compared with the outcome as chosen by a welfare-maximizing social planner, who internalizes the crowding effect. She solves the following maximization problem:

$$
\max _{n_{i}}\left[p_{p} n_{i}\left(\bar{V}-N n_{i} v\right)-c-\frac{k}{2}\left(p_{p} n_{i}\right)^{2} \sigma_{V}^{2}\right],
$$

yielding the following expression for the socially-optimal herd size for each pastoralist:

$$
\tilde{n}_{i}=\frac{\bar{V}}{2 N v+k p_{p} \sigma_{V}^{2}} .
$$

The social planner chooses a herd that is smaller than the output-maximizing herd, $\tilde{n}_{i}<\frac{\bar{V}}{2 N v}$, unless pastoralists are risk neutral (mimicked by $k=0$ ) or there is no stochasticity in the system $\left(\sigma_{V}^{2}=0\right)$. The negative externality argument implies that the unregulated common property will be "over-stocked" relative to the social optimum: $n_{i}^{*}>\tilde{n}_{i}$.

Result 1 In the absence of insurance, risk-averse pastoralists choose larger herds than the social planner in the short term.

\subsection{Introducing Insurance}

How does insurance affect the stocking rates chosen by planner and pastoralists? Assume that a novel index insurance product is introduced that pays out an amount $d$ in case the realized amount of rainfall falls below a certain threshold: $R \leq \underline{R}$, or the state of vegetation $V$ falls below $\underline{V}:=r_{1}+r_{2} \underline{R}$ [see (2)]. ${ }^{6}$ The insurance premium is denoted by $p$. If the insurance product is actuarially fair, its premium equals $p=F(\underline{V}) d$, where $F$ denotes the

\footnotetext{
${ }^{6}$ As is common in actual index-based insurance products, we assume that insurance pay-out is triggered by rainfall (which influences vegetation). In Kenya and Ethiopia, pay-outs in the index-based livestock insurance scheme are triggered by a remotely sensed Normalized Differential Vegetation Index (NDVI) measure.
} 
cumulative distribution function of $V$. In what follows we consider the case of an actuarially fair insurance product, but the analysis is readily extended to allow for products that are priced differently (e.g., subsidized insurance). Observe that we refrain from including basis risk-we assume that rainfall levels in the commons can be perfectly monitored.

Let us assume von Neumann-Morgenstern utilities and denote the two-outcome insurance lottery by $I$. After adopting insurance, expected utility of a farmer is given by

$$
E[U(I)]=F(\underline{V}) E[U(\pi+d-p) \mid V \leq \underline{V}]+(1-F(\underline{V})) E[U(\pi-p) \mid V>\underline{V}] .
$$

After some manipulation (see Appendix A.1) this may be rewritten as

$$
E[U(I)]=1-\beta\left(n_{i} ; d\right) e^{k p} e^{-k \pi\left(n_{i}, \mathbf{n}^{-i} ; \bar{V}\right)+\left(\frac{k^{2}}{2}\right) s_{2}\left(n_{i}\right)^{2} \sigma_{V}^{2}},
$$

where

$$
\beta\left(n_{i} ; d\right):=1-\left(1-e^{-k d}\right) \Phi\left(k s_{2}\left(n_{i}\right) \sigma_{V}+\frac{\underline{V}-\bar{V}}{\sigma_{V}}\right)
$$

with $\Phi(\cdot)$ the cumulative distribution function of the standard normal distribution. Observe that $0<\beta \leq 1$ and that if $d=0=p$, then (15) simplifies to (8). Other properties, needed for (21) below, are $\partial \beta / \partial n_{i}, \partial \beta / \partial d, \partial^{2} \beta / \partial n_{i} \partial d<0(d>0)$.

We ask how the adoption of insurance affects the optimal herd size and pastoralist welfare, and distinguish between three different institutional scenarios. First, we solve the market equilibrium where individual farmers are free to choose both coverage and stocks, ignoring congestion. Second, we will solve the social planner's problem, where the planner determines both coverage and stock size. Third, we consider a hypothetical "hybrid scenario" where the planner regulates coverage, and individual pastoralists choose the size of their herd-taking coverage $d$ (and hence premium $p$ ) as given.

\subsubsection{Case 1: The Market Outcome}

What happens if actuarially fair insurance can be purchased on the market? Pastoralists choose the utility-maximizing coverage level and associated privately optimal herd size, ignoring the congestion externality implied for other pastoralists. Each herder solves

$$
\max _{n_{i}, d_{i}}\left[1-\beta\left(n_{i} ; d_{i}\right) e^{k F(\underline{V}) d_{i}} e^{-k \pi\left(n_{i}, \mathbf{n}^{-i} ; \bar{V}\right)+\left(\frac{k^{2}}{2}\right) s_{2}\left(n_{i}\right)^{2} \sigma_{V}^{2}}\right] .
$$

The first-order condition for $d_{i}$ comes to

$$
\left[-\frac{1}{\beta\left(n_{i} ; d_{i}\right)} \frac{\partial \beta\left(n_{i} ; d_{i}\right)}{\partial d_{i}}\right]-k F(\underline{V})=0,
$$

capturing the marginal net return to insurance: the direct marginal gains due to smoothing (in brackets) minus the direct marginal costs of increasing the premium. This yields the following optimal level of insurance coverage in the case of a positive herd size:

$$
d_{i}=d^{* *}\left(n_{i}\right):=\frac{1}{k} \ln \left(\frac{\tilde{\Phi}^{i}(1-F(\underline{V}))}{\left(1-\tilde{\Phi}^{i}\right) F(\underline{V})}\right)>0,
$$


where $\tilde{\Phi}^{i}:=\Phi\left(k s_{2}\left(n_{i}\right) \sigma_{V}+\frac{\underline{\underline{V}} \bar{V}}{\sigma_{V}}\right)$. Note that $d^{* *}(0)=0$, since $\Phi\left(\frac{\underline{\underline{V}-\bar{V}}}{\sigma_{V}}\right)=F(\underline{V})$, and the derivative $d^{* * \prime}>0$. Hence, pastoralists choose a positive level of insurance coverage, and this level is increasing in own herd size.

The first-order condition for $n_{i}$ implicitly defines the optimal stock size in the presence of insurance:

$$
k \frac{\partial \pi\left(n_{i}, \mathbf{n}^{-i} ; \bar{V}\right)}{\partial n_{i}}-\frac{\partial}{\partial n_{i}}\left(\frac{k^{2}}{2} s_{2}\left(n_{i}\right)^{2} \sigma_{V}^{2}\right)-\frac{1}{\beta\left(n_{i} ; d_{i}\right)} \frac{\partial \beta\left(n_{i} ; d_{i}\right)}{\partial n_{i}}=0 .
$$

Let $n_{i}=n^{* *}\left(d_{i}\right)$ denote the unique solution of this equation after replacing $\mathbf{n}^{-i}$ with $(N-1) n_{i}$. Because $n^{* *}\left(d_{i}\right)$ is a differentiable function of $d_{i}$, we can analyze how the stock in the symmetric Nash equilibrium changes in response to changes in coverage level [using (5b)]:

$$
\frac{\partial n^{* *}}{\partial d_{i}}=\frac{\frac{\partial}{\partial d_{i}}\left[\frac{1}{\beta} \frac{\partial \beta}{\partial n_{i}}\right]}{k \frac{\partial^{2} \pi}{\partial n_{i}^{2}}-\left(k p_{p} \sigma_{V}\right)^{2}-(N-1) k p_{p} v-\frac{\partial}{\partial n_{i}}\left[\frac{1}{\beta} \frac{\partial \beta}{\partial n_{i}}\right]}>0 .
$$

The denominator of (21) is strictly negative on the assumption that the expected utility function (17) is strictly concave. With the above indicated properties of $\beta\left(n_{i} ; d_{i}\right)$, it is easy to show that also the numerator of $(21)$ is strictly negative. Insurance coverage invites pastoralists to increase herd size, so the adoption of insurance implies $n^{* *}\left(d_{i}\right)>n_{i}^{*}$ [see (11)]. The reason is that by reducing the volatility of herding profits, insurance increases the utility of having animals. Adding an animal to the pasture lowers the returns to all other animals owned by the pastoralist (and others). In case of a drought, returns per animal are low and the marginal utility of income is high. Concavity of the utility function implies that productivity losses during droughts have a relatively large downward effect on utility. The introduction of insurance stabilizes income, attenuating utility losses due to overgrazing during droughts.

Result 2 Actuarially fair insurance will be adopted by risk-averse pastoralists. It will stabilize their income, which invites them to increase their herd beyond the Nash-equilibrium level in the absence of insurance.

\subsubsection{Case 2: The Social Planner's Outcome}

A welfare-maximizing planner who can choose both coverage and stock size for each pastoralist solves the following problem:

$$
\max _{n_{i}, d_{i}}\left[1-\beta\left(n_{i} ; d_{i}\right) e^{k F(\underline{V}) d_{i}} e^{-k \pi\left(n_{i},(N-1) n_{i} ; \bar{V}\right)+\left(\frac{k^{2}}{2}\right) s_{2}\left(n_{i}\right)^{2} \sigma_{V}^{2}}\right] .
$$

Note that this is the same expression as (17), with $\mathbf{n}^{-i}$ replaced by $(N-1) n_{i}$. Taking the first derivative with respect to coverage produces the same condition as the one derived for individual pastoralists in (19). However, this does not imply that coverage levels are identical across institutional contexts. The reason is that farmers and planner choose herds of different sizes. This can be verified by taking the first derivative of (22) with respect to $n_{i}$ and equating this to zero: 


$$
k \frac{\partial \pi}{\partial \mathbf{n}^{-i}}(N-1)+k \frac{\partial \pi}{\partial n_{i}}-\frac{\partial}{\partial n_{i}}\left(\frac{k^{2}}{2} s_{2}\left(n_{i}\right)^{2} \sigma_{V}^{2}\right)-\frac{1}{\beta\left(n_{i} ; d_{i}\right)} \frac{\partial \beta\left(n_{i} ; d_{i}\right)}{\partial n_{i}}=0 .
$$

Comparing (20) with (23) provides insights in how optimal stock sizes differ across institutional contexts. Evaluating the left-hand side of (23) at $n_{i}=n^{* *}\left(d_{i}\right)$, we have $\frac{\partial \pi\left(n^{* *}\left(d_{i}\right),(N-1) n^{* *}\left(d_{i}\right) ; \bar{V}\right)}{\partial \mathbf{n}^{-i}}<0 .{ }^{7}$ Hence, assuming concavity (see Appendix A.2), we know that, for the same level of insurance coverage, the planner chooses a smaller herd than the herd in the symmetric Nash equilibrium. Denoting the solution of (23) as $n_{i}=\tilde{n}\left(d_{i}\right)$, we thus find

$$
\tilde{n}\left(d_{i}\right)<n^{* *}\left(d_{i}\right)
$$

To characterize the (short-term) equilibrium solutions as chosen by the planner and as eventuating on the market, observe that the planner's equilibrium $(\tilde{n}(\tilde{d}), \tilde{d})$ is defined by the intersection of two curves in an $\left(n_{i}, d_{i}\right)$-diagram: $n_{i}=\tilde{n}\left(d_{i}\right)$ and $d_{i}=d^{* *}\left(n_{i}\right)$. Both curves are upward-sloping, and $\tilde{n}(0)>0$ and $d^{* *}(0)=0$. Similarly, market equilibrium $\left(n^{* *}\left(d^{* *}\right), d^{* *}\right)$ is defined by the intersection of $n_{i}=n^{* *}\left(d_{i}\right)$ and $d_{i}=d^{* *}\left(n_{i}\right)$, with $n^{* *}(0)>0$ and $d^{* *}(0)=0$. We also know that (24) holds. Taken together this implies:

$$
\tilde{n}(\tilde{d})<n^{* *}\left(d^{* *}\right) \text { and } \tilde{d}<d^{* *} .
$$

Result 3 In the presence of insurance, the social planner will choose lower coverage and a smaller herd size than the market outcome in the Nash equilibrium.

In other words, in the market equilibrium pastoralists will be over-insured (relative to the optimal level of insurance) and the common grazing ground will be over-stocked.

\subsubsection{Case 3: The Hybrid Scenario}

The third case we consider involves the planner choosing insurance coverage and pastoralists choosing herd size. If the planner moves first, she seeks to balance two conflicting objectives with the insurance package: to smooth pastoralists' income and consumption (which directly increases welfare) whilst keeping in mind that increasing coverage will incentivize herders to increase their herd [as $\frac{\partial n^{* *}}{\partial d_{i}}>0$, see (21)]. The latter effect accentuates the pre-existing inefficiency due to the crowding externality. Intuitively, the planner should choose a level of coverage below what pastoralists would purchase on the market. We now explore this trade-off in more detail.

The planner chooses insurance coverage $d_{i}$ and premium $F(\underline{V}) d_{i}$ to maximize the payoff of pastoralists in a symmetric Nash equilibrium, knowing that pastoralists will respond by choosing the herd size that maximizes their utility. Her optimization problem is

\footnotetext{
7 Observe that the planner's solution is not equal to the (expected) output-maximizing stock level combined with "full insurance." The reason is that the index-based insurance product that we consider does not allow full income smoothing. For rainfall levels above $R$ income will fluctuate with the vagaries of realized rainfall without any insurance payouts. Since pastoralists are risk averse, this implies that seeking the stock that maximizes expected output will be inefficient.
} 


$$
\max _{d_{i}}\left[1-\beta\left(n^{* *}\left(d_{i}\right) ; d_{i}\right) e^{k F(\underline{V}) d_{i}} e^{-k \pi\left(n^{* *}\left(d_{i}\right),(N-1) n^{* *}\left(d_{i}\right) ; \bar{V}\right)+\left(\frac{k^{2}}{2}\right) s_{2}\left(n^{* *}\left(d_{i}\right)\right)^{2} \sigma_{V}^{2}}\right] .
$$

Let us denote this objective function by $W\left(d_{i}\right)$. Taking the first derivative with respect to $d_{i}$ implies $^{8}$

$$
\operatorname{sign}\left(W^{\prime}\left(d_{i}\right)\right)=\operatorname{sign}\left(k \frac{\partial \pi}{\partial \mathbf{n}^{-i}}(N-1) \frac{\partial n^{* *}}{\partial d_{i}}-\frac{1}{\beta} \frac{\partial \beta}{\partial d_{i}}-k F(\underline{V})\right) .
$$

The first term on the right-hand side captures the increase in the crowding externality due to insurance and has a negative sign. The sum of the second and third terms captures the marginal net return to insurance [see (18)]. The marginal net return is positive at low insurance levels and negative at high insurance levels. Because the overall effect cannot be $a$ priori signed at low coverage levels, there are two outcomes to consider (assuming concavity of $W$, see Appendix A.2).

First, if the crowding externality is so strong that $W^{\prime}(0) \leq 0$, the negative first term dominates the positive sum of the second and third terms, and $W\left(d_{i}\right)$ is a downward sloping curve. Pastoralist welfare is always decreasing in insurance coverage then, and the planner should optimally set $d_{i}=0$ to minimize herd size and congestion. While pastoralists would purchase some insurance on the market if it were available, the planner should ban access to it.

Second, it is also possible that $W^{\prime}(0)>0$, which represents the case where the marginal benefits of smoothing are larger, at low coverage levels, than the increased congestion externality caused by insurance. In this case, an inverted U-shaped relation between pastoralist welfare and coverage eventuates. This can be seen as follows. Recall that if the farmer is free to choose $n_{i}$ and $d_{i}$ (as in Case 1 above), the associated symmetric Nash equilibrium has $n_{i}=n^{* *}\left(d^{* *}\right)$ and $d_{i}=d^{* *}$. This implies that for $W^{\prime}$ evaluated at $d^{* *}$, it must hold $-\frac{1}{\beta} \frac{\partial \beta}{\partial d_{i}}-k F(\underline{V})=0$. Therefore, we know that

$$
\operatorname{sign}\left(W^{\prime}\left(d^{* *}\right)\right)=\operatorname{sign}\left(k \frac{\partial \pi}{\partial \mathbf{n}^{-i}}(N-1) \frac{\partial n^{* *}}{\partial d_{i}}\right)<0,
$$

that is, welfare $W\left(d_{i}\right)$ is a downward-sloping curve around and beyond the equilibrium coverage as emerging in the market outcome. Upon combining $W^{\prime}(0)>0$ and $W^{\prime}\left(d^{* *}\right)<0$, there must be a turning point $\hat{d}$, such that $0<\hat{d}<d^{* *}$, where the following condition holds: $W^{\prime}(\hat{d})=0$. This is the optimal level of insurance that is chosen by the planner if pastoralists are free to choose the size of their own herd. The coverage level is not only below the Nash equilibrium coverage purchased on the market $\left(d^{* *}\right)$, it is also below the coverage level $(\tilde{d})$ chosen by the planner if she could choose both $d_{i}$ and $n_{i}$. The reason for the latter is that the marginal welfare benefit from raising coverage in the hybrid scenario is smaller than in the planner's problem because insurance accentuates the crowding externality.

Result 4 For the hybrid institutional scenario where the planner chooses insurance coverage and pastoralists are free to choose the size of their herds, the optimal level of insurance coverage chosen by a planner is always below the level of coverage preferred by pastoralists. It may even be optimal for the planner to ban access to insurance (a corner solution).

${ }^{8}$ Applying (20), since pastoralists are free to choose the size of their herd. 
Combining the various intermediate results enables us to probe the welfare implications of insurance across institutional contexts. To this we now turn.

\subsection{Insurance and Welfare}

It is straightforward to compare welfare in Cases 1 and 3 to welfare in the planner's scenario. When pastoralists are free to choose herd size (and insurance coverage), they choose too many animals (and too much insurance coverage, if they can), compared to the planner's solution. As a result, welfare in Cases 1 and 3 must be (weakly) dominated by welfare in Case 2. Similarly, it is evident that welfare in Case 3 is higher than welfare in the market scenario, Case 1. It is more interesting to compare welfare in Cases 1 and 3 to welfare in the "no-insurance" scenario.

For the hybrid scenario, Case 3, insurance cannot reduce welfare-else the planner would simply choose $d_{i}=0$. For interior solutions $\left(d_{i}=\hat{d}\right)$ it must be the case that pastoralist welfare goes up, relative to the no-insurance benchmark.

Result 5 If the planner can regulate the market for insurance, then pastoralist welfare will (weakly) increase after the introduction of index-based drought insurance.

Matters are more complex, and interesting, in the symmetric Nash equilibrium as emerging in the context of free markets for insurance and livestock (Case 1). Welfare with insurance is lower than welfare in the no-insurance scenario if $W\left(d^{* *}\right)<W(0)$. This will necessarily happen if $W^{\prime}(0) \leq 0$, and the planner in Case 3 would prefer no insurance. It may also happen if $W^{\prime}(0)>0$, when the planner would opt for positive insurance $\hat{d}$. In the latter case, the more the congestion externality dominates the gains from smoothing, the more the free-market level of insurance $d^{* *}$ will overshoot the optimum level $\hat{d}$, thus increasing the likelihood that farmers are better off without the insurance option.

Result 6 In a setting where pastoralists can freely purchase insurance and choose the size of their herd, the short-term welfare effects of introducing insurance are fundamentally ambiguous due to opposing effects on the variance and level of income.

The scenario where pastoralists are free to choose the level of insurance coverage as well as the size of their herd most accurately describes the actual institutional context for most of the developing world. From a policy perspective, however, it seems prudent to regulate the insurance market and offer fixed packages with given levels of coverage below what markets would deliver.

\section{The Dynamic Model: Livestock and Vegetation}

Overgrazing has dynamic consequences in addition to the instantaneous crowding externality modelled above. We study these consequences for Case 1, or the scenario where pastoralists can choose both insurance coverage and herd size. This is the most interesting and realistic case, and also the scenario in which it is likely that decision-makers will discount the future at an infinite rate. Lack of property rights to land implies pastoralists ignore future benefits and essentially solve a series of static optimization problems. These static problems are interlinked via an equation of motion for the vegetation stock. 
Fig. 1 Long-run effects of insurance: two cases

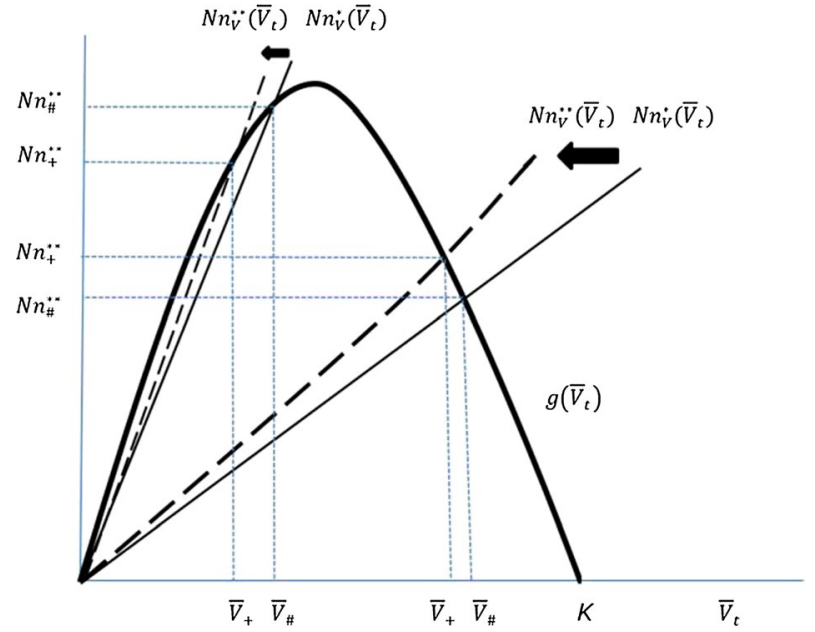

To introduce meaningful dynamics in the model we slightly augment vegetation Eq. (2):

$$
V_{t}=r_{1, t-1}+r_{2} R_{t}
$$

so for all time periods $t$ we know that the stock of vegetation is normally distributed with expected value $\bar{V}_{t}:=r_{1, t-1}+r_{2} \bar{R}$ and variance $r_{2}^{2} \sigma_{R}^{2}$. We assume that coefficient $r_{1, t-1}$ acts as a "shifter" of the vegetation dynamics. For a steady state, therefore, where the expected stock of vegetation remains unchanged, it must hold that $r_{1, t}=r_{1, t-1}$ for all $t$. Out-ofequilibrium dynamics are governed by the interplay of vegetation growth and grazing. We assume that over-grazing shifts the distribution of $V$ "to the left" without affecting its shape:

$$
r_{1, t}-r_{1, t-1}=g\left(\bar{V}_{t}\right)-\mathbf{n}_{t} .
$$

Here $g\left(\bar{V}_{t}\right)$ describes vegetation growth, and we have normalized the system such that each animal of the (equilibrium) total herd $\mathbf{n}_{t}$ consumes one unit of grass per period to enable production. We assume $g\left(\bar{V}_{t}\right)$ to be the well-known logistic function:

$$
g\left(\bar{V}_{t}\right):=\gamma \bar{V}_{t}\left(1-\frac{\bar{V}_{t}}{K}\right),
$$

so that expected vegetation growth is zero when $\bar{V}_{t}=0$ or $\bar{V}_{t}=K$, where $K$ is the so-called carrying capacity and $\gamma>0$ is the intrinsic growth rate. Expected vegetation growth takes on a maximum value for $\bar{V}_{t}=K / 2$. The logistic growth function is drawn in Fig. 1. For a steady state, expected vegetation growth should equal the total amount consumed by livestock, or:

$$
g\left(\bar{V}_{t}\right)=N n_{V}\left(\bar{V}_{t}\right)
$$

where $n_{V}\left(\bar{V}_{t}\right)$ is the (conditional) equilibrium herd size: $n_{V}^{*}\left(\bar{V}_{t}\right)$ for the case of no-insurance [given by the RHS of (11)] and $n_{V}^{* *}\left(\bar{V}_{t}\right)$ for the case with insurance (derived below).

We are now ready to explore the steady states of the grazing system. First consider the case without insurance, where animal holdings of individual pastoralists in the symmetric 
Nash equilibrium are given by (11). We can plot total consumption of pasture [or the RHS of (32)] against the expected stock of vegetation. The total herd of animals is a straight line from the origin with slope $N /\left[(N+1) v+k p_{p} \sigma_{V}^{2}\right]$. In Fig. 1 we have drawn two consumption lines for different combinations of parameters; one cutting the growth function to the left of the parabola's top $\left(\bar{V}_{\#}<K / 2\right)$, and one cutting the growth function to the right of the top $\left(K / 2<\bar{V}_{\text {\# }}<K\right)$.

If we assume that the intrinsic growth rate $\gamma$ is greater than the slope of the consumption line, the consumption line must cut the growth function from below, yielding a unique and stable equilibrium for the long-term vegetation and animal stock: $\left(\bar{V}_{\#}, N n_{\#}^{*}\right)$. In this steady state, potentially far below the rangeland carrying capacity $K$, expected vegetation growth equals consumption. Deviations from expected vegetation growth, due to stochastic rainfall realizations, imply that the system will hover around this steady state.

Next consider the case with insurance, where animal stocks in a short-term Nash equilibrium are defined by the intersection of $n_{i}=n^{* *}\left(d_{i}\right)$ and $d_{i}=d^{* *}\left(n_{i}\right)$. How does this short-term equilibrium adjust in response to changes in the expected stock of vegetation, caused by changes in the shifter $r_{1, t-1}$ ? It can be shown that $n^{* *}\left(d_{i}\right)$ is strictly increasing in $\bar{V}_{t}$, so we may write $n^{* *}\left(d_{i} ; \bar{V}_{t}\right)$, whereas $d^{* *}\left(n_{i}\right)$ remains constant over time for given herd size (see Appendix A.3). It implies that as $\bar{V}_{t}$ increases, in a new short-term equilibrium both $n^{* *}\left(d^{* *}\right)$ and $d^{* *}$ will take greater values. This is intuitive: pastoralists respond to greater abundance of expected forage by expanding their herd and, hence, coverage. This new equilibrium animal stock with insurance is denoted by

$$
n_{i, t}=n_{V}^{* *}\left(\bar{V}_{t}\right),
$$

which is a strictly increasing function with $n_{V}^{* *}(0)=0$ (because $\left.n^{* *}(0 ; 0)=0\right)$.

We know from the earlier analysis that, for every positive expected vegetation stock $\bar{V}_{t}$, the animal herd with insurance is greater than the animal herd without insurance: $n_{V}^{* *}\left(\bar{V}_{t}\right)>n_{V}^{*}\left(\bar{V}_{t}\right)$. In terms of Fig. 1 this automatically implies that the function $N n_{V}^{* *}\left(\bar{V}_{t}\right)$ lies above the no-insurance line $N n_{V}^{*}\left(\bar{V}_{t}\right)$. In other words, the system with insurance will "settle" at an equilibrium characterized by a smaller expected vegetation stock: $\bar{V}_{+}<\bar{V}_{\#}$, where $\bar{V}_{+}$is the steady-state vegetation stock in the case with insurance. Observe that this is true for both cases drawn in Fig. 1: the pre-insurance steady state may be to the left or the right of the top of the growth function.

Result 7 In the long run, the introduction of drought insurance will reduce the steady-state expected vegetation stock.

The vegetation stock is an important mediating variable for the impact of insurance on pastoralists' expected profits (or income) and welfare. To evaluate how insurance affects income we need to keep track of the dynamics of vegetation as well as herd size. From the logistic growth function follows immediately that the dynamics of herd size are conditional on the pre-insurance steady state. If the pre-insurance steady state $\left(\bar{V}_{\#}, N n_{\#}^{*}\right)$ is on the upward sloping segment of the growth function, $\bar{V}_{\#}<K / 2$, then the insurance-induced incentive for herd expansion (in the short run) will shift the steady state to the left and down the growth function. As is also evident from Fig. 1, the new equilibrium $\left(\bar{V}_{+}, N n_{+}^{* *}\right)$ will be characterized by less grass and smaller herds. Conversely, if the initial steady state is on the downward sloping part of the growth function, so that $\bar{V}_{\#}>K / 2$, a "not-too-large" decrease in the equilibrium vegetation stock implies that a greater animal stock can be supported ( since $\left.n_{+}=g\left(\bar{V}_{+}\right) / N\right)$. 
With multiple moving parts, an insurance intervention could backfire and possibly reduce expected income. Consider the most interesting case where $\bar{V}_{\#}<K / 2$, or the case with degraded grazing grounds and presumably vulnerable pastoralist groupsthe outcome most likely to be targeted by well-intended outside (insurance) interventions. Herd size and vegetation are both arguments in the pastoralist production function, and both are adversely affected by the introduction of insurance. An attenuating effect is due to the reduced (static) congestion externality, as other pastoralists will also keep fewer animals in the symmetric Nash equilibrium. Expected profits ultimately depend on the steady-state stock $\bar{V}_{t}$, according to $\pi\left(g\left(\bar{V}_{t}\right) / N,(N-1) g(\bar{V} t) / N ; \bar{V}_{t}\right)$. This third-order function is first strictly increasing and then strictly decreasing, reaching a unique maximum on $(K / 2, K)$ - the segment where the growth function is downward sloping (see Appendix A.4).

Hence, the net effect of introducing insurance in a context with depleted grazing lands, $\bar{V}_{\#}<K / 2$, will unambiguously lower pastoralist expected income. This results in the paradoxical outcome that under conditions where an intervention seems particularly needed, it will actually reduce pastoralist income.

The effects on expected income in the case of steady states on the downward sloping part of the growth function $\left(\bar{V}_{\#}>K / 2\right)$ are ambiguous, but from what we have argued above it is clear that the effect on income is only positive for (nearly) virgin grazing grounds where the vegetation stock is close to the system's carrying capacity, $K$. Outside interventions work best when they are needed least.

Result 8 The introduction of insurance has an ambiguous effect on pastoralist income, but if the grazing system is depleted such that the vegetation stock is below the maximum sustainable yield level $\left(\bar{V}_{\#}<K / 2\right)$ then the introduction of insurance will unambiguously reduce the expected income of pastoralists.

The long-run effects on well-being should also take the consumption smoothing effect into account-unambiguously beneficial to pastoralists. This means the net effect of insurance on utility is ambiguous on both the upward- and downward-sloping segments of the growth function. Since we know from Result 6 that the short-term welfare effects of the introduction of drought insurance are ambiguous, we now know the following:

Result 9 If the short-term welfare effect of the introduction of insurance is negative, the welfare loss will become worse in the long run as the vegetation stock shrinks. If the shortterm welfare effect of the introduction of insurance is positive, the welfare gain will diminish over time (and possibly be converted in a net loss) as the vegetation stock shrinks.

\subsection{A Simple Numerical Example}

We now sketch a simple numerical example to illustrate the fundamental ambiguity caused by the introduction of insurance. Using arbitrary parameter values, we solve for herd size and welfare in the long term (after vegetation has responded to changes in stock size). Results are provided in Fig. 2. Panel A provides the equilibrium herd for different levels of risk aversion $(k)$. Consider the case without insurance first. The relation between risk aversion and herd size is described by an inverted-U. For low levels of risk aversion, the system settles to the left of the top of the parabola in Fig. 1. Increasing $k$ shifts the equilibrium to 


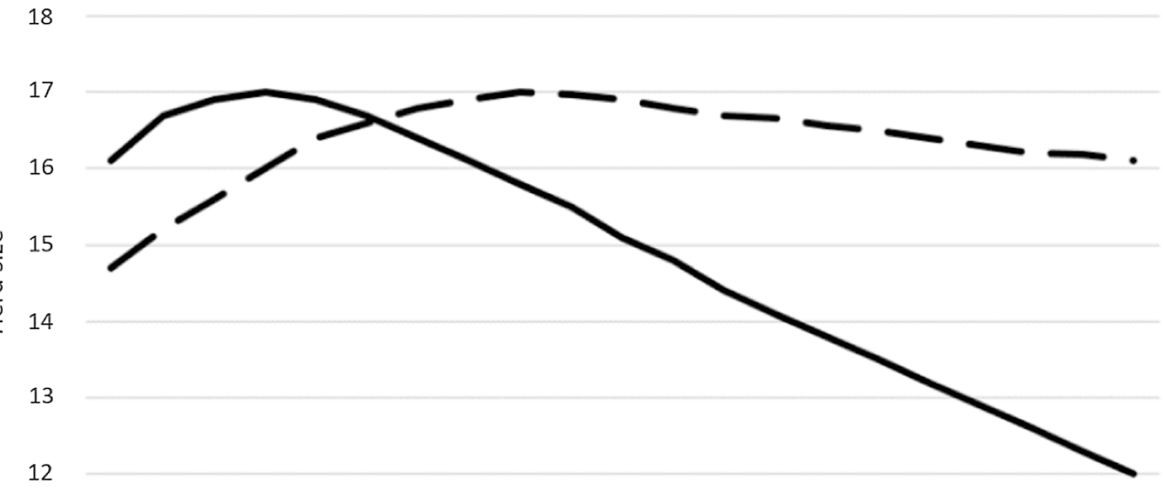

11

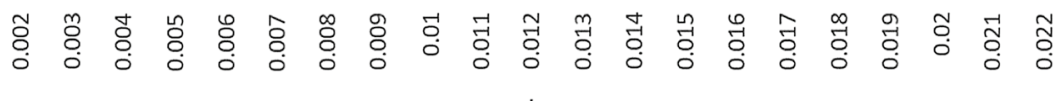

Panel A: The relation between long-run herd size and risk aversion

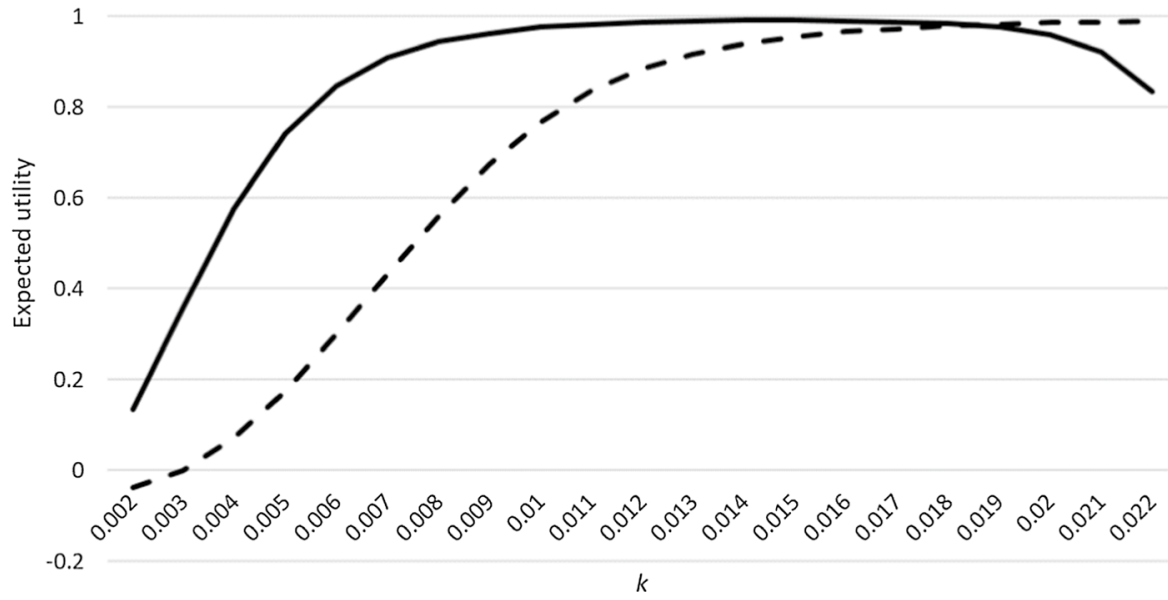

Panel B: The relation between long-run welfare and risk aversion

Fig. 2 Long-run effects of insurance on herd size and welfare (Dashed curves refer to the case of insurance; for parameters, see Appendix)

the right, and herd size increases until the equilibrium reaches the top. Vegetation growth is maximized for $k \approx 0.005$ at which level it can support a steady state herd size of 17 animals per pastoralist. Further increasing risk aversion implies a shift further to the right, with grass production and herd size both falling. 
We know that, in the short run (given vegetation stock), insurance increases herd sizethe insurance isocline lies above the no-insurance isocline (as in Fig. 1). For low values of $k$ ( $k \lesssim 0.007$ ), in equilibrium, herd size and vegetation stock are therefore smaller. Increasing $k$ implies shifting the system "to the right", so it approaches and eventually passes the top. Grass production and herd size first increase, and then decrease. The relationship between risk aversion and equilibrium herd size with insurance mirrors the relationship without insurance, but the herd reaches its maximum size for a higher value of $k$ (at $k \approx 0.01$ ). Hence, pastoralists have larger herds in the steady state with insurance than without insurance if they are "sufficiently risk averse" (i.e. $k \gtrsim 0.007$, where the curves intersect). Else, the reverse is true.

In Panel B we compute equilibrium welfare levels for different levels of risk aversion (different system steady states). These outcomes capture the potentially opposing effects of insurance on welfare- the consumption smoothing properties make herders better off, but the grazing externalities may lower (expected) income. For parameter values in Fig. 2, the income-reducing effect dominates unless pastoralists are sufficiently risk averse $(k \gtrsim 0.018$ ) .

\section{Discussion}

The theoretical model yields several testable hypotheses that can be brought to the data. For example, the introduction of insurance will increase short-term stocking rates, decrease the long-term vegetation stock, and have an effect on pastoralist income that is declining in insurance coverage. However, testing these predictions using real data is complicated by the stylized nature of our models. To zoom in on the negative externality induced by incomplete property rights we have omitted several other features of pastoral systems. The effect of relaxing some of these simplifying assumptions is readily discussed.

For example, including basis risk or transaction costs will reduce the net benefits pastoralists can expect from adoption-reducing uptake and attenuating the various effects associated with insurance-induced herd expansion. In contrast, subsidizing insurance by offering it at below-actuarially fair prices will stimulate uptake and accentuate these effects. Allowing pastoralists to invest in animal quality by providing veterinary care, as documented by Jensen et al. (2017), opens up avenues for intensification that do not involve congestion externalities or overgrazing.

Other extensions are more difficult to accommodate. For example, we assume away preferences that would lead to precautionary savings in kind. Work by, for example, Deaton $(1991,1994)$ and Carroll (1997) suggests that households hold wealth to self-protect against near-term income shocks (in settings with and without liquidity constraints, respectively). If monetary savings are impractical, households accumulate assets instead-typically animals in the case of pastoral households. Lybbert et al. (2004) found that greater pre-drought herd size is correlated with greater post-drought herd size, suggesting that herd accumulation can be an effective coping strategy. ${ }^{9}$ Formal insurance could reduce reliance on self-insurance through "buffer-stock saving", attenuating crowding externalities.

\footnotetext{
${ }^{9}$ Marketing of animals usually plays a smaller role to moderate shocks. The reason is that drought shocks are covariate, increasing aggregate supply and depressing prices on imperfectly integrated livestock markets. Fafchamps et al. (1998) document that livestock sales typically compensate for only $15-30 \%$ of income shortfalls due to village-level shocks.
} 
Jensen et al. (2017) provide some support for this hypothesis, and document a negative causal effect of accumulated past coverage on current herd size in Northern Kenya (but herd size is not negatively affected by current insurance coverage). The interpretation of this result is not straightforward. Nevertheless, we acknowledge that formal insurance may not only increase the risk-adjusted returns to livestock holding but also decrease demand for livestock as a mechanism for precautionary savings. For some pastoralists the former effect will dominate, and for others the latter, so that the net effect on aggregate herd size is ambiguous. This is an important qualification to our results, complicating "crisp" delineation of the parameter space in which insurance reduces expected pastoral income. But of course it does not diminish our main insight that the income and welfare effects of insurance in the context of ill-defined property rights are fundamentally ambiguous, and probably context-specific. ${ }^{10}$

Our approach to capturing herd and vegetation dynamics is also a simplification of reality. Essentially we have borrowed a standard renewable resource model with densitydependent vegetation growth, and augmented it by introducing stochastic rainfall. Biotic processes associated with vegetation growth and animal grazing determine the dynamics of the system, and abiotic processes (rainfall) introduce stochasticity around the unique interior solution ("equilibrium") that emerges. Another modeling approach, advanced by Ellis and Swift (1988) and others, emphasizes the non-equilibrial (but persistent) nature of pastoral systems and the regulatory role of abiotic perturbations (non-feedback controls such as droughts) rather than grazing pressure. Such models rely on state-and-transition and disequilibrium models.

The relative importance of abiotic versus biotic controls for system dynamics is debated and presumably location- or system-specific (e.g. distant pastures versus lands around towns and water points). McPeak (2003) analyzes resource heterogeneity and localized degradation of a common pasture. Grazing externalities and droughts may also interact, so that the common property nature of the grazing system magnifies drought-induced livestock cycles (Fafchamps et al. 1998). Our dynamic model is relevant for contexts where overstocking and overgrazing affect vegetation stocks and growth, and irrelevant for contexts fully governed by abiotic factors. The presence of heavily degraded pockets of land due to overstocking in specific locations suggests the relevance of our approach for certain patches of the overall grazing system.

\section{Conclusions}

In the eyes of many observers, index insurance holds the promise of transforming the agricultural landscape in Africa. By linking insurance pay-outs to verifiable indices correlated with actual production losses, index insurance may mitigate or even eliminate transaction costs, asymmetric information problems and bottlenecks for reinsurance on international capital markets. If remaining constraints for diffusion can be addressed, such as basis risk and smallholders' lack of familiarity with insurance products, then large-scale adoption

\footnotetext{
${ }^{10}$ Observe that variation in the context provides additional opportunities for empirical testing. For example, buffer stocks are most valuable when markets are regionally integrated (local markets may collapse after a weather shock if many farmers simultaneously supply their excess animals). The adverse implications due to negative externalities predicted by our model will particularly eventuate in contexts with spatially-segmented markets where buffer stocks are not so helpful and the precautionary motive is therefore relatively unimportant.
} 
may follow. Until now, significant uptake of insurance products only occurs when these products are subsidized. Policy makers need to trade-off the expected benefits and costs of an expanding insurance market. The potential benefits of such a scenario for the lives of African smallholders are well-documented in the literature. These include enhanced opportunities for consumption smoothing and coping with shocks as well as incentives for modernization. The promise extends to both smallholder farmers as well as pastoralists.

We do not wish to downplay the importance of any of these potential benefits. However, we point to a potential downside of insurance in the (realistic) context of imperfect institutions, which is a direct consequence of the theory of the second best. Economists have known since pioneering work by Lipsey and Lancaster (1956) that addressing one departure from optimality in the presence of remaining imperfections may make matters worse. ${ }^{11}$ Hence ambiguous outcomes eventuate when the market for insurance is "fixed" if other optimality conditions cannot be satisfied simultaneously.

To illustrate this general principle, we explore the case of index-based livestock insurance in the presence of commonly-managed pastures. Assuming utility-maximizing herders, we show that index insurance reduces own production risk of overstocking, and invites congestion externalities (in the short run) as well as degradation of grasslands (in the long run). The idea that insurance can increase herd size is consistent with observations in Ethiopia (Matsuda et al. 2019). We find that government regulation can improve outcomes, relative to the market solution where pastoralists can freely choose insurance coverage and herd size. Ideally, the government should choose both coverage and herd size, but such an scenario of far-reaching intervention is likely unrealistic. More realistically, we find that regulating the insurance market by "capping" coverage below the level that would be chosen by pastoralists on the free market (and leave pastoralist free to choose herd size), weakly improves farmer welfare.

Taking the environmental dynamics into account, we show that the introduction of insurance always invites a reduction of pasture quality. This effect follows directly from the incentive to expand herd size. If the pre-insurance system was characterized by a vulnerable population of herders on a degraded pasture, then the introduction of insurance will unambiguously make herders poorer. Welfare effects of insurance are fundamentally ambiguous, but necessarily worse in the long run than in the short run. This could suggest an alternative explanation for the low uptake of index insurance in contexts with imperfect property rights to important environmental resources: strong cultural rules, or strong local chiefs, may discourage the uptake of index insurance as a social planner would if there is some awareness of the tragedy of the commons issue at the local level.

The model is simple and ignores many features that are important in real life settings. Including such features would result in additional complexity but is unlikely to alter the main insight that the income and welfare effects of the introduction of insurance are ambiguous. Future research could analyze these models, and perhaps also include additional (non-market) costs associated with pasture degradation, such as loss of biodiversity or wild species (which further complicate assessing the full costs and benefits of upscaling insurance). We wish to draw attention to these potential effects so that future efforts to "roll out the insurance agenda" or subsidize specific insurance products can be based on a better understanding of the short- and long-term implications.

\footnotetext{
11 For example, Chichilnisky (1994) and Brander and Taylor (1997) demonstrated that liberalizing trade may lower welfare "in the South" if property rights to natural resources are not defined.
} 


\section{Appendix}

\section{A.1 Derivation of (15)}

To simplify notation, let $\mu:=\bar{V}, \sigma:=\sigma_{V}$, and $w:=k s_{2}$. Recall that $\Phi$ is the distribution function of the standard normal distribution. First we prove the following result:

Lemma 1 With $b:=(\underline{V}-\mu) / \sigma$, it holds

$$
E\left(e^{-w V} \mid V \leq \underline{V}\right)=E\left(e^{-w V}\right) \cdot \frac{\Phi(w \sigma+b)}{\Phi(b)} . \prec
$$

Proof By definition, with $F$ the cumulative distribution function of the normal distribution,

$$
E\left(e^{-w V} \mid V \leq \underline{V}\right)=\frac{\int_{-\infty}^{\frac{V}{-}} e^{-w V} d F(V)}{\int_{-\infty}^{V} d F(V)} .
$$

For the denominator it holds

$$
\int_{-\infty}^{\underline{V}} d F(V)=F(\underline{V})=\Phi\left(\frac{\underline{V}-\mu}{\sigma}\right)=\Phi(b),
$$

and the numerator can be written as

$$
\int_{-\infty}^{\underline{V}} e^{-w V} d F(V)=\int_{-\infty}^{\underline{V}} \frac{1}{\sigma \sqrt{2 \pi}} e^{-w V-\frac{1}{2}\left(\frac{V-\mu}{\sigma}\right)^{2}} d V .
$$

Now let $\mu^{\prime}:=\mu-w \sigma^{2}$, so that

$$
\begin{aligned}
w V+\frac{1}{2 \sigma^{2}}(V-\mu)^{2} & =\frac{1}{2 \sigma^{2}}\left[V^{2}-2 \mu V+\mu^{2}+2 w V \sigma^{2}\right] \\
& =\frac{1}{2 \sigma^{2}}\left[V^{2}-2\left(\mu-w \sigma^{2}\right) V+\left(\mu-k w \sigma^{2}\right)^{2}+2 \mu w \sigma^{2}-\left(w \sigma^{2}\right)^{2}\right] \\
& =\frac{1}{2 \sigma^{2}}\left[\left(V-\mu^{\prime}\right)^{2}+w \sigma^{2}\left(2 \mu-w \sigma^{2}\right)\right] .
\end{aligned}
$$

Using this, the numerator becomes

$$
\begin{aligned}
\int_{-\infty}^{\underline{V}} \frac{1}{\sigma \sqrt{2 \pi}} e^{-w V-\frac{1}{2}\left(\frac{V-\mu}{\sigma}\right)^{2}} d V & =\int_{-\infty}^{\underline{V}} \frac{1}{\sigma \sqrt{2 \pi}} e^{-\frac{1}{2 \sigma^{2}}\left[\left(V-\mu^{\prime}\right)^{2}+w \sigma^{2}\left(2 \mu-w \sigma^{2}\right)\right]} d V \\
& =e^{-w \mu+\left(w^{2} / 2\right) \sigma^{2}} \cdot \int_{-\infty}^{\frac{V}{\sigma}} \frac{1}{\sqrt{2 \pi}} e^{-\frac{1}{2}\left(\frac{V-\mu^{\prime}}{\sigma}\right)^{2}} d V \\
& =E\left(e^{-w V}\right) \cdot \Phi\left(\frac{V-\mu^{\prime}}{\sigma}\right)=E\left(e^{-w V}\right) \cdot \Phi(w \sigma+b) .
\end{aligned}
$$

The derivation of (15) is straightforward enough using this lemma and the two following results: 


$$
\begin{aligned}
E[u(\pi+d-p) \mid V \leq \underline{V}] & =\frac{\int_{-\infty}^{\underline{V}}\left[1-e^{-k\left(s_{1}+s_{2} V+d-p\right)}\right] d F(V)}{\int_{-\infty}^{\underline{V}} d F(V)} \\
& =\frac{F(\underline{V})-e^{-k\left(s_{1}-p\right)} e^{-k d} \int_{-\infty}^{\underline{V}} e^{-k s_{2} V} d F(V)}{F(\underline{V})} \\
& =1-e^{-k\left(s_{1}-p\right)} e^{-k d} \cdot E\left(e^{-k s_{2} V} \mid V \leq \underline{V}\right) \\
E[u(\pi-p) \mid V>\underline{V}] & =\frac{\int_{\underline{V}}^{\infty}\left[1-e^{-k\left(s_{1}+s_{2} V-p\right)}\right] d F(V)}{\int_{\underline{V}}^{\infty} d F(V)} \\
& =\frac{1-F(\underline{V})-e^{-k\left(s_{1}-p\right)} \int_{\underline{V}}^{\infty} e^{-k s_{2} V} d F(V)}{1-F(\underline{V})} \\
& =1-\frac{1}{1-F(\underline{V})} e^{-k\left(s_{1}-p\right)}\left(\int_{-\infty}^{\infty} e^{-k s_{2} V} d F(V)-\int_{-\infty}^{\underline{V}} e^{-k s_{2} V} d F(V)\right) \\
& =1-\frac{1}{1-F(\underline{V})} e^{-k\left(s_{1}-p\right)}\left(E\left(e^{-k s_{2} V}\right)-F(\underline{V}) E\left(e^{-k s_{2} V} \mid V \leq \underline{V}\right)\right) .
\end{aligned}
$$

\section{A.2 Concavity of the Objective Functions (17)-(26)}

First, consider (17). It is convenient to define $\left(n, d, \mathbf{n}^{-i} \geq 0\right)$ :

$$
h\left(n, d ; \mathbf{n}^{-i}\right):=1-\beta(n ; d) e^{k d \theta} e^{X\left(n ; \mathbf{n}^{-i}, \bar{V}\right)}
$$

where $\theta:=F(\underline{V})$ and

$$
X\left(n ; \mathbf{n}^{-i}, \bar{V}\right):=-k \pi\left(n, \mathbf{n}^{-i} ; \bar{V}\right)+\left(k^{2} / 2\right) g_{2}(n)^{2} \sigma_{V}^{2} .
$$

Differentiation with respect to $n$ and $d$ gives (subscripts denote partial derivatives)

$$
h_{n}=-e^{k d \theta} e^{X}\left[\beta X_{n}+\beta_{n}\right] \text { and } h_{d}=-e^{k d \theta} e^{X}\left[\beta k \theta+\beta_{d}\right],
$$

so that for an interior maximum it must hold $\beta X_{n}+\beta_{n}=0$ and $\beta k \theta+\beta_{d}=0$. The secondorder conditions for a global maximum require that

$$
h_{n n}, h_{d d}<0 \text { and } h_{n n} h_{d d}-h_{n d}^{2}>0,
$$

where the second-order derivatives are

$$
\begin{aligned}
& h_{n n}=-e^{k d \theta} e^{X}\left(X_{n}\left[\beta X_{n}+\beta_{n}\right]+\beta_{n} X_{n}+\beta X_{n n}+\beta_{n n}\right) \\
& h_{d d}=-e^{k d \theta} e^{X}\left(k \theta\left[\beta k \theta+\beta_{d}\right]+\beta_{d} k \theta+\beta_{d d}\right) \\
& h_{n d}=-e^{k d \theta} e^{X}\left(k \theta\left[\beta X_{n}+\beta_{n}\right]+\beta_{d} X_{n}+\beta_{n d}\right)
\end{aligned}
$$

These conditions require that $h$ is strictly concave in a neighbourhood of the maximum. The conditions: $h_{n n}, h_{d d}<0$, evaluated at a point where the first-order conditions hold can be expressed as

$$
\beta_{n} X_{n}+\beta X_{n n}+\beta_{n n}>0 \text { and } \beta_{d} k \theta+\beta_{d d}>0
$$

Note that 


$$
\begin{aligned}
\frac{1}{\beta}\left[\beta_{n} X_{n}+\beta X_{n n}+\beta_{n n}\right] & =X_{n n}+\frac{\partial\left(\beta_{n} / \beta\right)}{\partial n} \\
& =-k \pi_{n n}+\left(k p_{p} \sigma_{V}\right)^{2}+\frac{\partial\left(\beta_{n} / \beta\right)}{\partial n},
\end{aligned}
$$

which is positive for large enough $p_{p}$ [see also (21)]. Further,

$$
\beta_{d} k \theta+\beta_{d d}=-k e^{-k d} \tilde{\Phi}^{i} k \theta+k^{2} e^{-k d} \tilde{\Phi}^{i}=k^{2} e^{-k d} \tilde{\Phi}^{i}[1-\theta],
$$

which is always positive for $\theta<1$.

As for objective function (22), define

$$
l(n, d):=h(n, d ;(N-1) n) .
$$

The first-order conditions for an interior maximum of $l$ and the sufficient conditions for strict concavity are as before, once we make the substitutions:

$$
\begin{aligned}
& X_{n} \rightarrow X_{n}+X_{\mathbf{n}^{-i}}(N-1) \\
& X_{n n} \rightarrow X_{n n}+2 X_{n \mathbf{n}^{-i}}(N-1)+X_{n \mathbf{n}^{-i}}(N-1)^{2} .
\end{aligned}
$$

Note that $X_{\mathbf{n}^{-i}}>0$ and $X_{n \mathbf{n}^{-i}}>0$.

Finally, objective function (26) can be written as

$$
W(d)=l\left(n^{* *}(d), d\right),
$$

where $n=n^{* *}(d)$ is the solution of $h_{n}(n, d ;(N-1) n)=0$. The first derivative is

$$
W^{\prime}(d)=l_{n} \frac{\partial n^{* *}}{\partial d}+l_{d}
$$

and the second-order condition for a maximum is

$$
W^{\prime \prime}(d)=\left(l_{n n} \frac{\partial n^{* *}}{\partial d}+l_{n d}\right) \frac{\partial n^{* *}}{\partial d}+l_{n} \frac{\partial^{2} n^{* *}}{\partial d^{2}}+l_{d n} \frac{\partial n^{* *}}{\partial d}+l_{d d}<0 .
$$

Substituting $-l_{d} / l_{n}$ for $\partial n^{* *} / \partial d$ (which holds in the case of an interior maximum), the latter requirement becomes

$$
\left(\frac{1}{l_{n}}\right)^{2}\left[l_{n n} l_{d}^{2}+l_{d d} l_{n}^{2}-2 l_{n d} l_{n} l_{d}\right]+l_{n} \frac{\partial^{2} n^{* *}}{\partial d^{2}}<0 .
$$

If the term in brackets is negative, then $l(n, d)$ is strictly quasi-concave. The sign of $\partial^{2} n^{* *} / \partial d^{2}$ depends on third-order derivatives of $\beta(n ; d)$.

\section{A.3 Properties of $n_{V}^{* *}\left(\bar{V}_{t}\right)$}

To prove that $n_{V}^{* *}(\bar{V})$ is strictly increasing, we show first that $d^{* *}(n)$ does not depend on $\bar{V}$ and then that $n^{* *}(d)$ is strictly increasing in $\bar{V}$. For this it is assumed that changes in $\bar{V}$ are caused by changes in $r_{1}$; recall $V=r_{1}+r_{2} R$ and that the distribution of $R$ is exogenously fixed, so changes in the distribution of $V$ are caused by a change in $r_{1}$. 
Noting (19), the influence of the distribution of $V$ on $d^{* *}(n)$ is captured by the ratio $b:=(\underline{V}-\bar{V}) / \sigma_{V}$ in $\Phi\left(k s_{2}(n)+b\right)$ and $F(\underline{V})=\Phi(b)$. Now

$$
b=\frac{\left(r_{1}+r_{2} \underline{R}\right)-\left(r_{1}+r_{2} \bar{R}\right)}{\sigma_{V}}=\frac{r_{2}(\underline{R}-\bar{R})}{\sigma_{V}},
$$

which is a constant independent of $r_{1}$. Hence, $d^{* *}(n)$ is constant.

Next, $n=n^{* *}(d)$ is the solution of

$$
\beta(n ; d) X_{n}(n ;(N-1) n, \bar{V})+\beta_{n}(n ; d)=0
$$

(see A.2 for notation). Since $\beta(n ; d)=1-\left(1-e^{-k d}\right) \Phi\left(k s_{2}(n)+b\right), \beta$ and $\beta_{n}$ do not depend on $r_{1}$. Differentiation of (A.2) gives

$$
\left[X_{n n}+(N-1) X_{n \mathbf{n}^{-i}}+\frac{\partial\left(\beta_{n} / \beta\right)}{\partial n}\right] d n+\frac{\partial X_{n}}{\partial \bar{V}} \frac{\partial \bar{V}}{\partial r_{1}} d r_{1}=0
$$

Now

$$
\frac{\partial X_{n}(n,(N-1) n)}{\partial \bar{V}}=\frac{\partial}{\partial \bar{V}}\left(-k\left[\pi_{n}+\pi_{\mathbf{n}^{-i}}(N-1)\right]+k^{2} s_{2}(n) \frac{\partial s_{2}}{\partial n} \sigma_{V}^{2}\right)=-k p_{p},
$$

$\frac{\partial \bar{V}}{\partial r_{1}}=1$, and $d r_{1}=d \bar{V}$. Therefore, we find

$$
\frac{d n}{d \bar{V}}=\frac{\partial n^{* *}}{\partial \bar{V}}=\frac{k p_{p}}{X_{n n}+(N-1) X_{n \mathbf{n}^{-i}}+\frac{\partial\left(\beta_{n} / \beta\right)}{\partial n}}>0
$$

where the positive sign of the denominator follows from second-order condition (A.1) [see also (21)] together with $X_{n \mathbf{n}^{i}}>0$.

\section{A.4 Properties of the Long-Run Profit Function}

Define a function $\pi_{L}:[0, K] \rightarrow \mathbb{R}$ given by $\pi_{L}(\bar{V}):=\pi(g(\bar{V}) / N,(N-1) g(\bar{V}) / N ; \bar{V})$ and note that $\pi_{L}$ is a third-order polynomial [see (3) and (32)]. Differentiation with respect to $\bar{V}$ yields

$$
\pi_{L}^{\prime}=p_{p} g^{\prime} \frac{1}{N}(\bar{V}-g v)+p_{p} g \frac{1}{N}\left(1-g^{\prime} v\right)
$$

so that

$$
\operatorname{sign}\left(\pi_{L}{ }^{\prime}\right)=\operatorname{sign}\left(g^{\prime} \bar{V}+g-2 g g^{\prime} v\right) .
$$

To evaluate (A.3), note first that a positive sign obtains if $g^{\prime}=0$, since $g(K / 2)>0$. Now suppose $g^{\prime}>0$. Because a symmetric Nash equilibrium has $\bar{V}>g v$, it holds

$$
g^{\prime} \bar{V}+g-2 g g^{\prime} v>g^{\prime} \bar{V}+g-2 g^{\prime} \bar{V}=-g^{\prime} \bar{V}+g .
$$

Because $g^{\prime} \bar{V}=g-\gamma \frac{\bar{V}^{2}}{K}$, we find 


$$
-g^{\prime} \bar{V}+g=-g+\gamma \frac{\bar{V}^{2}}{K}+g=\gamma \frac{\bar{V}^{2}}{K}>0
$$

Hence, $\pi_{L}$ is strictly increasing on $[0, K / 2]$.

Next suppose $g^{\prime}<0$. Note that $g(K)=0$ and $g^{\prime}(K)=-\gamma$. Evaluated in $\bar{V}=K$, we therefore have

$$
g^{\prime} \bar{V}+g-2 g g^{\prime} v=-\gamma K<0,
$$

implying that $\pi_{L}$ is strictly decreasing in a left neighbourhood of $\bar{V}=K$.

Combining results and noting that a third-order function has at most one maximum, $\pi_{L}$ must have a unique interior maximum, and this is located on $(K / 2, K)$.

\section{A.5 Parameters of the Numerical Example in Fig. 2}

$p=1 ; c=50 ; \nu=0.001 ; N=4000 ; \sigma_{V}=20 ; \underline{V}=60 ; \gamma=1360 ; K=200$.

Acknowledgements We thank the editor for helpful suggestions, but remain responsible for the content of this paper. There is no funding to acknowledge.

\section{Declaration}

Conflicts of interest The authors declare that they have no conflict of interest.

Open Access This article is licensed under a Creative Commons Attribution 4.0 International License, which permits use, sharing, adaptation, distribution and reproduction in any medium or format, as long as you give appropriate credit to the original author(s) and the source, provide a link to the Creative Commons licence, and indicate if changes were made. The images or other third party material in this article are included in the article's Creative Commons licence, unless indicated otherwise in a credit line to the material. If material is not included in the article's Creative Commons licence and your intended use is not permitted by statutory regulation or exceeds the permitted use, you will need to obtain permission directly from the copyright holder. To view a copy of this licence, visit http://creativecommons.org/licenses/by/4.0/.

\section{References}

Ahmed S, McIntosh C, Sarris A (2017) The impact of commercial rainfall index insurance: experimental evidence from Ethiopia. UCSD Working paper

Baland J-M, Platteau JP (1996) Halting degradation of natural resources: is there a role for rural communities?. Clarendon Press, Oxford

Binswanger HP (2012) Is there too much hype about index-based agricultural insurance? J Dev Stud 48:187-200

Bjerge B, Trifkovic N (2018) Extreme weather and demand for index insurance in rural India. Eur Rev Agric Econ 45:397-431

Bocqueho G, Jacquet F, Reynaud A (2014) Expected utility or prospect theory maximisers? Assessing farmers' risk behaviour from field-experiment data. Eur Rev Agric Econ 41:135-172

Boucher S, Carter M, Guirkinger C (2008) Risk rationing and wealth effects in credit markets: theory and implications for agricultural development. Am J Agric Econ 90:409-423

Brander J, Taylor MS (1997) International trade and open access renewable resources: the small open economy case. Can J Econ 30:526-552

Cai H, Chen Y, Fang H, Zhou L-A (2015) The effect of microinsurance on economic activities: evidence from a randomized field experiment. Rev Econ Stat 97:287-300 
Cai J, Song C (2017) Do disaster experience and knowledge affect insurance take-up decisions? J Dev Econ 124:83-94

Cai J (2016) The impact of insurance provision on household production and financial decisions. Am Econ J Econ Policy 8:44-82

Carroll C (1997) Buffer-stock saving and the life cycle/permanent income hypothesis. Quart J Econ 112:1-55

Carter M, de Janvry A, Sadoulet E, Sarris A (2017) Index insurance for developing country agriculture: a reassessment. Annu Rev Resour Econ 9:10.1-10.18

Casaburi L, Willis J, (2016) Time vs state in insurance: experimental evidence from contract farming in Kenya. University of Zurich, UBS International Center of Economics in Society, Working Paper No. 18

Castell H (2017) Livestock insurance gains ground in Africa. Spore Mag. http://spore.cta.int/en/article/lives tock-insurance-gains-ground-in-africa.html

Chantarat S, Barrett CB, Mude AG, Turvey C (2007) Using weather index insurance to improve drought response for famine prevention. Am J Agric Econ 89:1262-1268

Chantarat S, Mude A, Barrett C, Carter M (2013) Designing index based livestock insurance for managing asset risk in northern Kenya. J Risk Insur 80:205-237

Chantarat S, Mude A, Barrett C, Turvey C (2017) Welfare impacts of index insurance in the presence of a poverty trap. World Dev 94:119-138

Chichilnisky G (1994) North-south trade and the global environment. Am Econ Rev 84:851-874

Christiaensen L, Demery L, Kuhl J (2010) The (evolving) role of agriculture in poverty reduction: an empirical perspective. UNU-WIDER Working Paper \#2010/36

Clarke D (2016) A theory of rational demand for index insurance. Am Econ J Microecon 8:283-306

Cole S, Gine X, Tobacman J, Topalova P, Townsend R, Vickerey J (2014) Barriers to household risk management: evidence from India. Am Econ J Appl Econ 5:104-135

Deaton A (1991) Saving and liquidity constraints. Econometrica 59:1221-1249

Deaton A (1994) Household saving in LDCs: credit markets, insurance and welfare. Scand J Econ 94:253-273

Dercon S, Vargass Hill R, Clarke D, Outes-Leon I, Taffesse A (2014) Offering rainfall insurance to informal groups: evidence from a field experiment in Ethiopia. J Dev Econ 106:132-143

Elabed G, Carter M (2015) Compound-risk aversion, ambiguity and the willingness to pay for microinsurance. J Econ Organ Behav 118:150-166

Elabed G, Bellemare M, Carter M, Guirkinger C (2013) Managing basis risk with multiscale index insurance. Agric Econ 44:419-431

Ellis J, Swift D (1988) Stability of African pastoral ecosystems: alternative paradigms and implications for development. J Range Manag 450-459

Emerick K, de Janvry A, Sadoulet E, Dar M (2016) Technological innovations, downside risk, and the modernization of agriculture. Am Econ Rev 106:1537-1561

Fafchamps M, Udry C, Czukas K (1998) Drought and saving in West Africa: are livestock a buffer stock? J Dev Econ 55:273-305

Foster AD, Rosenzweig M (2010) Microeconomics of technology adoption. Annu Rev Econ 2:395-424

Haggblade S, Hazell P, Dorosh P (2007) Sectoral growth linkages between agriculture and the rural nonfarm economy. In: Haggblade S, Hazell P, Reardon T (eds) Transforming the rural nonfarm economy: opportunities and threats in the developing world. The Johns Hopkins University Press, Baltimore

Hazell P, Anderson J, Balzer N, Hastrup-Clemmensen A, Hess U, Rispoli F (2010) Potential for scale and sustainability in weather index insurance for agriculture and rural livelihoods. International Fund for Agricultural Development, and World Food Programme, Rome

Jensen N, Barrett C, Mude A (2016) Index insurance quality and basis risk: evidence from Northern Kenya. Am J Agric Econ 98:1450-1469

Jensen N, Barrett C, Mude A (2017) Cash transfers and index insurance: a comparative analysis from Northern Kenya. J Dev Econ 129:14-28

Jensen N, Mude A, Barrett C (2018) How basis risk and spatiotemporal adverse selection influence demand for index insurance: evidence from Northern Kenya. Food Policy 74:172-198

Karlan D, Osei R, Osei-Akoto I, Udry C (2014) Agricultural decisions after relaxing risk and credit constraints. Quart J Econ 129:597-652

Lipsey R, Lancaster K (1956) The general theory of second best. Rev Econ Stud 24:11-32

Lybbert T, Barrett C, Desta S, Coppock D (2004) Stochastic wealth dynamics and risk management among a poor population. Econ J 114:750-777

Matsuda A, Takahashi K, Ikegami M (2019) Direct and indirect impact of index-based livestock insurance in southern Ethiopia. Geneva Pap Risk Insur Issues Pract 44:481-502 
McPeak J (2003) Analyzing and addressing localized degradation in the commons. Land Econ 79:515-536

Mobarak AM, Rosenzweig M (2013) Informal risk sharing, index insurance and risk taking in developing countries. Am Econ Rev (P\&P) 103:375-380

Sarris A (2013) Weather index insurance for agricultural development: introduction to the special issue. Agric Econ 44:381-384

Shen Z, Odening M, Okhrin O (2016) Can expert knowledge compensate for data scarcity in crop insurance pricing? Eur Rev Agric Econ 43:237-269

Walker T, Ryan J (1990) Village and household economies in India's semiarid tropics. Johns Hopkins University Press, Baltimore

World Bank (2007) World Bank Report 2008: Agriculture for Development. The World Bank, Washington $\mathrm{DC}$

Publisher's Note Springer Nature remains neutral with regard to jurisdictional claims in published maps and institutional affiliations. 